\title{
VIABILIDADE DE BORBULHAS DE CITROS COLETADAS DE AMBIENTE PROTEGIDO E MANTIDAS EM FRIGOCONSERVAÇÃO ${ }^{1}$
}

\author{
HARDI SCHMATZ MACIEL ${ }^{2}$, PAULO VITOR DUTRA DE SOUZA ${ }^{3}$, GILMAR SCHÄFER $^{4}$
}

RESUMO -Este trabalho teve como objetivo estudar a manutenção da viabilidade das borbulhas de laranjeira 'Valência' e tangerineira 'Montenegrina', oriundas de ambiente protegido, sob diferentes processos de desinfestação e períodos de armazenamento em câmara fria, assim como avaliar o comportamento das substâncias de reserva contidas nos ramos porta-borbulhas nos diferentes períodos de armazenamento. $\mathrm{O}$ experimento foi conduzido em câmara fria com temperatura em torno de $5^{\circ} \mathrm{C}$, onde se testaram borbulhas de duas cultivares de citros (Montenegrina e Valência), três tratamentos químicos (testemunha, 1 aplicação e 2 aplicações de fungicida - Captan $\left.10 \mathrm{~g} \mathrm{~L}^{-1}\right)$ e três períodos de armazenamento (0;90 e 180 dias), com quatro repetições. As borbulhas da cultivar Montenegrina mantiveram-se viáveis por 90 dias sem tratamento com fungicida e por, no mínimo, 180 dias se submetidas a 1 tratamento com fungicida. As borbulhas da cultivar Valência mantiveram-se viáveis por, no mínimo, 180 dias sem a necessidade de tratamento com fungicida. As substâncias de reserva dos ramos porta-borbulhas da tangerineira 'Montenegrina' sofreram redução ao longo do armazenamento.

Termos para indexação: Cítrus, enxertia, propagação.

\section{VIABILITY OF CITRUS BUD COLLECTED FROM GREENHOUSE AND KEPT IN REFRIGERATED STORAGE}

\begin{abstract}
This work aimed to study bud viability maintenance of 'Valencia' orange and 'Montenegrina' Mandarin, derived from greenhouse plants under different disinfestations processes and cold storage periods. Another objective was to evaluate the behavior of substances of reserve contained in the stem in different periods of storage. The experiment was lead in cold chamber with temperature around $5^{\circ} \mathrm{C}$. It was tested two citrus varieties (Montenegrina mandarin and Valencia orange), three chemical treatments (control, 1 application and 2 applications of fungicide - Captan $\left.10 \mathrm{~g} \mathrm{~L}^{-1}\right)$ and three storage periods (0, 90, and 180 days), with four replications. The results demonstrated that buds of 'Montenegrina' mandarin had been remained viable per 90 days without fungicide and for 180 days if submitted at one fungicide application. The buds from 'Valência' orange had been remained viable for 180 days without fungicide treatment. The reserve substances of 'Montenegrina' mandarin stem reduced along the storage period.
\end{abstract}

Index terms: Citrus, grafting, propagation.

\section{INTRODUÇÃO}

Atualmente, as mudas cítricas produzidas em muitos viveiros no Rio Grande do Sul não apresentam garantias genéticas e fitossanitárias. No entanto, devido ao surgimento de novas pragas e moléstias cada vez mais preocupantes no cenário da citricultura, torna-se necessário estabelecer mudanças no sistema de produção de mudas para evitar sua contaminação. A alternativa passa por manter plantas-matrizes e borbulheiras registradas e produzir as mudas em ambiente protegido, que, apesar de aumentar o preço das mudas, qualifica-as com um melhor padrão varietal e fitossanitário, contribuindo para o desenvolvimento da citricultura no Rio Grande do Sul (Fochesato, 2005). Nas borbulheiras, apesar de se conseguir bom controle da intensidade de brotações e do fluxo de crescimento, nem sempre se consegue sincronia perfeita entre o período de amadurecimento dos ramos e o momento em que os porta-enxertos estão aptos à enxertia. Assim, faz-se necessário o armazenamento dos ramos porta-borbulhas, a fim de maximizar o aproveitamento das borbulhas, ampliar o período de oferta e dinamizar o uso de mãode-obra nas borbulheiras. $\mathrm{O}$ armazenamento refrigerado permite a conservação dos ramos porta-borbulhas por vários meses, embora ocorra perda gradual de viabilidade das borbulhas (Lima et al., 2002).

Devido ao considerável desenvolvimento da citricultura gaúcha nos últimos anos, a demanda por borbulhas cresceu. Como a oferta de borbulhas produzidas em ambiente protegido ainda é pequena para o atendimento da demanda total, fica ainda mais evidente a importância no máximo aproveitamento desses materiais.

'(Trabalho 071-07). Recebido em: 22-03-2007. Aceito para publicação: 19-09-2007.

${ }^{2}$ Eng. Agrônomo, Ms, Programa de Pós-Graduação em Fitotecnia, Faculdade de Agronomia, UFRGS, Av. Bento Gonçalves, 7712, Caixa Postal 15.100, CEP 91.501-970, Porto Alegre-RS.

${ }^{3}$ Eng. Agrônomo, Dr., Prof. Adjunto, Faculdade de Agronomia da UFRGS, Av. Bento Gonçalves 7712, CEP 91501-970, Porto Alegre-RS. E-mail: pvdsouza@ufrgs.br. Bolsista CNPq.

${ }^{4}$ Eng. Agr., Dr., Bolsista Pós-doutorado Junior CNPq, Faculdade de Agronomia da UFRGS, Av. Bento Gonçalves 7712, CEP 91501-970, Porto Alegre-RS E-mail: gilmarschafer@hotmail.com 
Ao viveirista interessa saber durante quanto tempo a viabilidade das borbulhas pode ser mantida, bem como qual o melhor processo de desinfestação para preservá-las, a fim de poder programar adequadamente as enxertias.

Segundo Bergamin Filho et al. (1995), as baixas temperaturas não eliminam os patógenos que estão dentro ou fora dos tecidos dos vegetais frescos. Apenas retardam ou inibem o crescimento dos patógenos. Dessa forma, há redução do desenvolvimento das infecções e evita-se o início de novas. Muitas vezes, as baixas temperaturas isoladamente não são insuficientes para um controle adequado das doenças, havendo necessidade do emprego de métodos suplementares.

Neste sentido, o presente trabalho teve por objetivo estudar a manutenção da viabilidade das borbulhas contidas em ramos de laranjeira 'Valência' (Citrus sinensis Osbeck) e de tangerineira 'Montenegrina' (Citrus deliciosa Tenore), oriundas de ambiente protegido, sob diferentes processos de desinfestação e armazenamento em câmara fria.

\section{MATERIAL E MÉTODOS}

$\mathrm{O}$ experimento foi conduzido em câmara fria, com temperatura média de $5^{\circ} \mathrm{C}$, no Laboratório de Biotecnologia em Horticultura do Departamento de Horticultura e Silvicultura da Faculdade de Agronomia da UFRGS.

Os ramos porta-borbulhas utilizados foram de laranjeira 'Valência' (Citrus sinensis Osbeck) e de tangerineira 'Montenegrina' (Citrus deliciosa Tenore) cultivadas na Borbulheira de Citros da Estação Experimental Agronômica da Universidade Federal do Rio Grande do Sul (EEA/UFRGS), rodovia BR 290, Km 146 em Eldorado do Sul - RS. As borbulheiras recebiam tratamentos fitossanitários quinzenalmente com produtos à base de cobre, visando a prevenir moléstias fúngicas e bacterianas.

Os ramos porta-borbulhas foram colhidos com tesoura de poda em agosto de 2004, com idade aproximada de 4 a 8 meses. No momento da coleta, as folhas foram retiradas, deixandose apenas os pecíolos com tamanho de $0,5 \mathrm{~cm}$. O tamanho dos ramos foi padronizado para aproximadamente $30 \mathrm{~cm}$ de comprimento e, em virtude de terem fluxos vegetativos diferentes, portanto diferentes diâmetros, em todos os tratamentos, foram distribuídos o mesmo número de ramos com características semelhantes.

Para o transporte até o laboratório, os ramos foram envoltos em jornal umedecido com água e acondicionados em sacos de polietileno.

Empregou-se o delineamento experimental completamente casualisado, em esquema fatorial $2 \times 3 \times 3$, com quatro repetições, para a análise de viabilidade, sendo cada parcela constituída de oito borbulhas. Avaliaram-se duas cultivares: Montenegrina e Valência; três tratamentos de desinfestação: Testemunha (apenas água), Fungicida 1 aplicação (Captan 500 PM -tratado no dia da coleta) e Fungicida 2 aplicações (tratado no dia da coleta e aos 45 dias de armazenamento, após a queda total dos pecíolos) na concentração de $10 \mathrm{~g} \mathrm{~L}^{-1}$; e três períodos de armazenamento: 0 ; 90 e 180 dias. Após a aplicação dos tratamentos, por imersão, durante 10 minutos nas soluções com os fungicidas, os ramos foram secados em temperatura ambiente, à sombra, e colocados nas embalagens de polietileno, com espessura de 0,07 micra, que foram fechadas hermeticamente e mantidas nas prateleiras da câmara fria na posição horizontal.

Nos três períodos de armazenamento, avaliou-se a viabilidade das borbulhas, bem como os teores de substâncias de reserva nos ramos porta-borbulhas. A viabilidade das borbulhas foi determinada pelo percentual de brotação das mesmas em cultivo in vitro. Os ramos porta-borbulhas foram colocados em tubos de ensaio de $100 \mathrm{~mL}$, com a base imersa em $20 \mathrm{~mL}$ do meio nutritivo Hoagland e Arnon (1950). Para isso, estes foram escovados com detergente neutro em água corrente e, posteriormente, tratados com álcool $70 \%$ durante 1 minuto e, em seguida, tratados com hipoclorito de sódio $1 \%$, durante 10 minutos. Ambos os tratamentos foram feitos por imersão dos ramos em provetas contendo as soluções. A seguir, fez-se a tríplice lavagem dos ramos com água deionizada. Com o auxílio de uma tesoura de poda e uma pinça, foram descartadas a borbulha do ápice e a da base os ramos e, em seguida, estes foram divididos em duas porções, de tal forma que cada um contivesse seis borbulhas. Cada segmento foi posto em um tubo de ensaio. Uma borbulha ficou submersa no meio e as outras cinco ficaram de fora. A seguir, os tubos de ensaio foram fechados com papel alumínio e fita plástica e colocados em uma câmara de brotação com controle de luminosidade (16 horas de luz) e temperatura $\left(27,5^{\circ} \mathrm{C}\right)$. No $13^{\circ}$ dia, fez-se a avaliação do percentual de borbulhas brotadas e a avaliação do tamanho das brotações. Para fins de contagem do percentual de brotação das borbulhas, a que estava imersa no meio nutritivo e a situada logo acima foram desconsideradas.

A análise de substâncias de reserva, devido à carência de material, foi determinada apenas na cultivar Montenegrina, segundo adaptações do método descrito por Priestley, adaptado por Souza (1990), que basicamente consistem em submeter uma amostra seca e triturada do tecido a uma digestão com uma solução aquosa de $5 \%$ de ácido tricloroacético e $35 \%$ de metanol, sendo a diferença da massa inicial para a final o teor de substâncias de reserva que as amostras continham. Para isso empregou-se um delineamento completamente casualisado em esquema fatorial $3 \times 3 \times 3$, com três repetições, sendo cada parcela constituída de um ramo porta-borbulhas. Avaliaram-se três partes dos ramos (base, meio e ápice), os três tratamentos de desinfestação e os três períodos de armazenamento, citados anteriormente.

As médias foram submetidas à análise de variância e comparadas pelo teste de Tukey, ao nível de 5\% de significância. O teor de substâncias de reserva foi submetido à análise de regressão.

\section{RESULTADOS E DISCUSSÃO}

No presente estudo, optou-se por realizar o teste de viabilidade das borbulhas in vitro, através da forçagem da brotação dos ramos porta-borbulhas. Essa opção justifica-se pelo fato de que o teste de viabilidade mediante a enxertia direta das 
borbulhas a campo sofre grande influência das condições climáticas, normalmente mascarando os resultados. Ao empregarse o cultivo in vitro, eliminam-se efeitos negativos externos.

Os resultados do teste realizado antes do armazenamento (dia zero) indicaram que as borbulhas de tangerineira 'Montenegrina' e laranjeira 'Valência' utilizadas no experimento apresentavam elevada qualidade, com brotação média de 90,6\% das borbulhas, para ambas as cultivares (Tabela 1).

Ocorreram interações significativas entre cultivar e armazenamento, tratamento químico e armazenamento, cultivar e tratamento químico.

A porcentagem de brotação das borbulhas da tangerineira 'Montenegrina' foi afetada significativamente pelo tempo de armazenamento e pelo tratamento químico (Tabela 1). Observa-se que, até os 90 dias de armazenamento, as borbulhas da tangerineira 'Montenegrina' mantinham-se viáveis, com brotação média das borbulhas semelhante à média da brotação inicial, independentemente do tratamento químico. Aos 180 dias, observou-se que a totalidade das borbulhas não-tratadas perdeu sua viabilidade, devido à contaminação dos ramos portaborbulhas por microrganismos.

Através de uma análise visual, aos 135 dias de armazenamento, observou-se que algumas parcelas do tratamento-testemunha da cultivar Montenegrina apresentavam sintomas de escurecimento nos tecidos das extremidades dos ramos e escurecimento das borbulhas. Foram os primeiros sintomas visuais de deterioração dos ramos, dentro dos períodos avaliados. Sintomas semelhantes foram descritos por Lima et al. (2002) e Bissoli et al. (1988).

Neste mesmo período, os ramos porta-borbulhas da cultivar Montenegrina, tratados com 1 e/ou 2 aplicações de fungicida, apresentavam a mesma coloração inicial. Visualmente, estavam em ótimo estado, o que foi confirmado com o teste de viabilidade aos 180 dias de armazenamento (Tabela 1), diferindo estatisticamente da testemunha nesta data.

Teixeira et al. (1971) observaram que a perda da viabilidade das borbulhas se intensificara à medida que as hastes perderam sua cor verde característica e adquiriram tonalidade marrom cada vez mais intensa. Os referidos autores relacionaram este fato à penetração de fungos.

A conservação de produtos vegetais sob refrigeração é limitada pela capacidade de alguns patógenos em conseguir desenvolver-se pouco acima do ponto de congelamento dos vegetais, como é o caso de Botrytis cinerea, Cladosporium herbarum, Penicillium expansum e Alternaria spp. (Eckert e Sommer, 1967). A baixa temperatura diminui a atividade desses microrganismos, porém não a inibe. Entretanto, a ação conjunta de baixas temperaturas e a aplicação de fungicidas aumentam o tempo de prevenção da infecção (Luvisi e Sommer, 1960).

Segundo Galli \& Guirado (1993), a limpeza e a assepsia dos ramos, tornando-os isentos de microrganismos patogênicos e saprófitas, podem aumentar a viabilidade de borbulhas armazenadas, exatamente o que ocorreu com a cultivar Montenegrina no presente estudo. Romeiro et al. (2001) verificaram que, independentemente da aplicação ou não de fungicidas (Benomyl, Captan e Iprodione), detectaram a ocorrência de fungos, dos gêneros Penicillium, Curvularia e Epicoccum, em menos de 2\% dos ramos de laranjeira 'Natal' armazenados. Os mencionados autores atribuíram a ausência de efeito dos fungicidas ao bom estado sanitário inicial dos ramos, em conseqüência do manejo adequado da borbulheira e, também, com a época de inverno em que eles foram colhidos.

Lima et al. (2002) observaram que, durante o armazenamento de ramos porta-borbulhas da limeira ácida 'Tahiti' [C. latifolia (Yu Tanaka) Tanaka], estes apresentaram sintomas de escurecimento dos tecidos nas extremidades e escurecimento das borbulhas, o que impossibilitou a enxertia de várias parcelas após 74 dias de armazenamento. Os sintomas descritos por eles foram semelhantes aos observados nos ramos da cultivar Montenegrina neste experimento.

A manutenção da viabilidade das borbulhas da cultivar Valência foi constatada até os 180 dias de armazenamento, período máximo de avaliação do experimento, indicando um potencial da cultivar para atingir maiores períodos de armazenamento, pois, na última avaliação, as borbulhas ainda apresentavam coloração verde e boa aparência. Sua porcentagem de brotação não foi afetada significativamente pelo tempo de armazenamento nem pelo tratamento químico, sendo que, aos 180 dias de armazenamento, o percentual médio de brotação das borbulhas dos três tratamentos foi de 89,6\% (Tabela 1). Esses resultados podem estar relacionados a uma característica própria das cultivares utilizadas. Bissoli et al. (1988) atribuíram as diferenças no comportamento de quatro espécies cítricas: laranjeira 'Natal' (C. sinensis Osb.), tangerineira 'Cravo' (C. reticulata Blanco), limeira ácida 'Tahiti' [C. latifolia (Yu Tanaka) Tanaka] e limoeiro 'Siciliano' (C. limon Burn.), a possíveis diferenças na estrutura anatômica de cada espécie.

Acontece que, com um diâmetro médio de $4,4 \mathrm{~mm}$, os ramos porta-borbulhas da tangerineira 'Montenegrina' eram muito finos, se comparados com os ramos da laranjeira 'Valência' utilizados no presente estudo ( $6,05 \mathrm{~mm}$ de diâmetro). Os ramos da tangerineira 'Montenegrina' eram mais tenros, o que, segundo Bissoli et al. (1998), pode predispor à deterioração mais rápida por ataque de fungos, que foi observado na tangerineira 'Cravo' que, dentre as quatro espécies cítricas por eles estudas, foi a que apresentou maior perda de viabilidade das borbulhas no final do período de conservação (63 dias).

Os ramos porta-borbulhas da laranjeira 'Valência' apresentaram-se com diâmetro maior se comparados aos ramos da tangerineira 'Montenegrina', o que pode ter resultado em maior longevidade natural das borbulhas. Bissoli et al. (1998) atribuíram ao limoeiro 'Siciliano' a característica de rusticidade que, dentre as quatro espécies cítricas estudadas pelos autores, apresentou a maior viabilidade das borbulhas aos 63 dias de conservação (maior que 70\%).

Na Tabela 2, observa-se que o tamanho médio das brotações da tangerineira 'Montenegrina' foi menor do que da laranjeira 'Valência', não sendo demonstrada diferença significativa entre os tratamentos químicos com fungicida. Tampouco houve diferença significativa entre os períodos de armazenamento. Esta semelhança no desenvolvimento das brotações, ao longo do período de armazenamento, demonstra a 
importância de testar a viabilidade das borbulhas in vitro, pois, assim, podem-se manter estáveis a temperatura e a UR do ambiente, fatores difíceis de controlar quando os testes de viabilidade são feitos mediante enxertia no viveiro.

A porcentagem de substâncias de reserva nos ramos porta-borbulha da tangerineira 'Montenegrina' foi afetada significativamente pelo tempo de armazenamento, porém não a foi pelo tratamento químico (Figura 1). Os resultados do teste preliminar, realizado antes do armazenamento (dia zero), indicaram que os ramos de tangerineira 'Montenegrina' apresentavam teor médio de substâncias de reserva de 25,6\%. Aos 90 dias de armazenamento, os ramos mostraram perda de substâncias de reserva, sendo que o teor médio baixou para $20,2 \%$, correspondendo a uma redução de $21,1 \%$ em relação ao início do experimento. Entretanto, dos 90 aos 180 dias de armazenamento, o teor de substâncias de reserva manteve-se estável, possibilitando que as borbulhas ainda se mantivessem viáveis. Esta estabilidade deve estar relacionada a uma provável diminuição dos níveis de oxigênio dentro da embalagem, resultantes de processos de respiração nos primeiros 90 dias de armazenagem.

Bissoli et al. (1988), em seus estudos com quatro espécies cítricas, observaram que as borbulhas conservadas por período mais longo apresentaram redução progressiva da viabilidade e deduziram que isso decorre do continuado processo metabólico de respiração, com desdobramento de substâncias de reserva e, ainda, que a baixa temperatura diminui essa atividade, mas não a anula, o que é confirmado no presente estudo. Entretanto, observa-se que as borbulhas da tangerineira 'Montenegrina', do tratamento-testemunha, apresentaram perda de viabilidade devido ao desenvolvimento de microrganismos contaminantes, o que não permitiu a análise de substâncias de reserva nos mesmos.

Na Figura 2, estão relacionadas as curvas de regressão dos teores de substâncias de reserva em diferentes posições dos ramos porta-borbulha, ao longo do período de armazenamento. Verificou-se que, originalmente, há maior teor de substâncias de reserva no ápice em comparação à base dos ramos; porém essa diferença desapareceu ao longo do armazenamento.

Alguns estudos evidenciam que essa diferença parece ser irrelevante do ponto de vista do pegamento e desenvolvimento dos enxertos. Por exemplo, Teixeira et al. (1971), em seus estudos com laranjeira 'Natal', combinaram seis períodos de conservação $(0 ; 4 ; 8 ; 12 ; 16$ e 20 dias $)$, com cinco situações originais das borbulhas ao longo das hastes (borbulha situada no ápice da haste, segunda borbulha a partir do ápice, terceira borbulha a partir do ápice, quarta borbulha a partir do ápice e borbulha situada na base da haste). Os autores não encontraram diferenças no desenvolvimento dos enxertos, em relação à posição das borbulhas da haste.

Segundo a Citrograf Mudas (2005), excluindo-se uma borbulha de cada extremidade do ramo porta-borbulhas, todas as outras existentes no ramo são consideradas viáveis à enxertia, não existindo diferença no pegamento ou desenvolvimento de gemas provenientes da ponta, meio ou base dos ramos, independentemente de serem frescas ou quando armazenadas por 20 dias.

TABELA 1 - Percentual de brotação das borbulhas, em ramos porta-borbulhas de tangerineira 'Montenegrina' e laranjeira 'Valência', produzidas em ambiente protegido e armazenadas em câmara fria.

\begin{tabular}{ccccc}
\hline \multirow{2}{*}{ Cultivar } & Tratamento & \multicolumn{3}{c}{ Dias de armazenamento } \\
\cline { 4 - 5 } Montenegrina & Químico & 0 & 90 & 180 \\
& Testemunha & $90,6 \mathrm{Aa}^{\mathrm{l}}$ & $90,6 \mathrm{Aa}$ & $00,0 \mathrm{Bb}$ \\
& $\begin{array}{c}\text { Fungicida 1 } \\
\text { aplicação }\end{array}$ & $90,6 \mathrm{Aa}$ & $93,8 \mathrm{Aa}$ & $93,8 \mathrm{Aa}$ \\
& $\begin{array}{c}\text { Fungicida 2 } \\
\text { aplicações }\end{array}$ & $90,6 \mathrm{Aa}$ & $96,9 \mathrm{Aa}$ & $93,8 \mathrm{Aa}$ \\
\hline \multirow{3}{*}{ Valência } & $\begin{array}{c}\text { Testemunha } \\
\text { Fungicida 1 }\end{array}$ & 90,6 & 90,6 & 87,5 \\
& $\begin{array}{c}\text { aplicação } \\
\text { Fungicida 2 } \\
\text { aplicações }\end{array}$ & 90,6 & 96,9 & 90,6 \\
\hline CV (\%) & & & 96,9 & 90,6 \\
\hline
\end{tabular}

Médias seguidas por letra maiúscula distintas nas linhas e letra minúscula distintas nas colunas diferem entre $\mathrm{si}$, a $5 \%$ de probabilidade, pelo teste de Tukey.

TABELA 2 - Tamanho médio das brotações ( $\mathrm{cm}$ ) em ramos portaborbulhas de tangerineira 'Montenegrina' e laranjeira 'Valência', cultivados in vitro, após armazenamento em câmara fria.

\begin{tabular}{|c|c|c|c|}
\hline \multirow{2}{*}{ Cultivar } & \multirow{2}{*}{$\begin{array}{l}\text { Tratamento } \\
\text { químico }\end{array}$} & \multicolumn{2}{|c|}{ Dias de armazenamento } \\
\hline & & 90 & 180 \\
\hline \multirow{3}{*}{ Montenegrina } & Testemunha & $1,2 b^{1}$ & - \\
\hline & $\begin{array}{c}\text { Fungicida } 1 \\
\text { aplicação }\end{array}$ & $1,1 \mathrm{~b}$ & $1,1 \mathrm{~b}$ \\
\hline & $\begin{array}{c}\text { Fungicida } 2 \\
\text { aplicações }\end{array}$ & $1,3 \mathrm{~b}$ & $1,1 \mathrm{~b}$ \\
\hline \multirow{3}{*}{ Valência } & Testemunha & $2,2 \mathrm{a}$ & $2,2 \mathrm{a}$ \\
\hline & $\begin{array}{l}\text { Fungicida } 1 \\
\text { aplicação }\end{array}$ & $2,2 \mathrm{a}$ & $2,0 \mathrm{a}$ \\
\hline & $\begin{array}{c}\text { Fungicida } 2 \\
\text { aplicações }\end{array}$ & $2,2 \mathrm{a}$ & $2,1 \mathrm{a}$ \\
\hline CV (\%) & & 30,1 & \\
\hline
\end{tabular}

${ }^{1}$ Médias seguidas pela mesma letra nas colunas não diferem entre si, a $5 \%$ de probabilidade, pelo teste de Tukey.

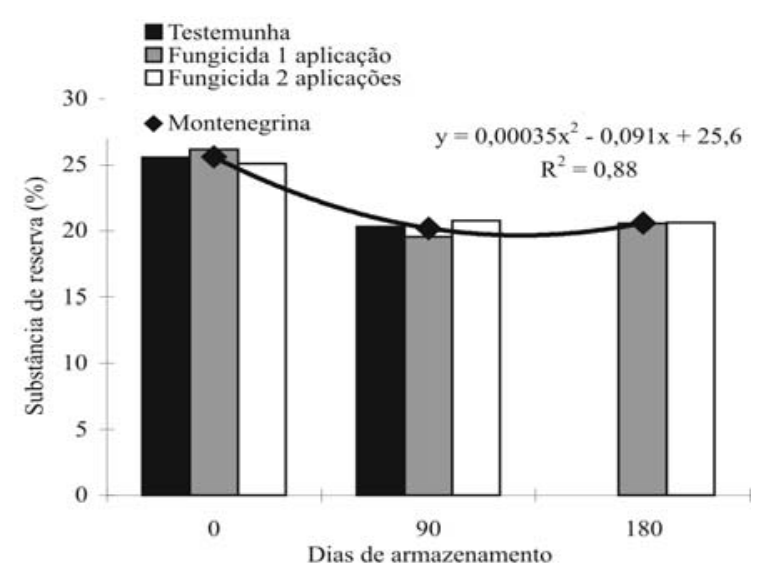

FIGURA 1 - Teor médio das substâncias de reserva (\%) dos tratamentos testemunha, 1 aplicação e 2 aplicações de fungicida e média de ramos porta-borbulhas da tangerineira 'Montenegrina', ao longo do período de armazenamento em câmara fria. 


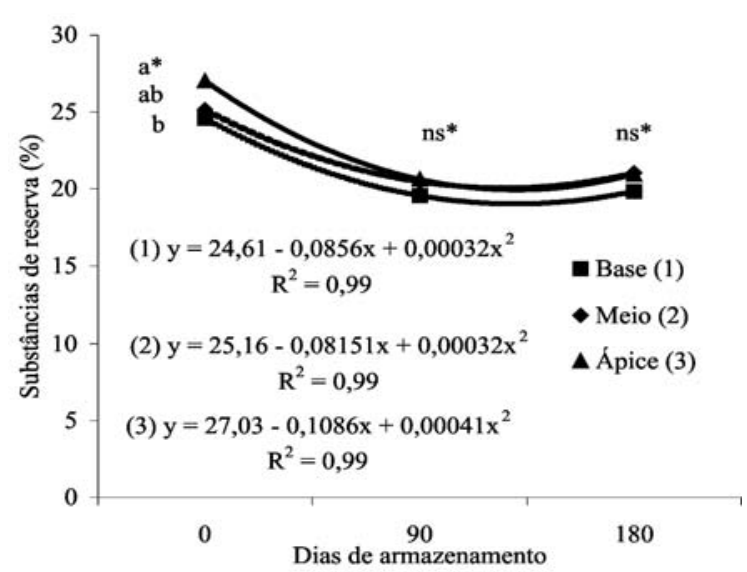

FIGURA 2 - Teor médio de substâncias de reserva (\%) na base, meio e ápice de ramos porta-borbulhas da tangerineira 'Montenegrina', ao longo do período de armazenamento em câmara fria. *Teste de Tukey, a $5 \%$ de probabilidade de erro, para as médias da porção do ramo no período de armazenagem avaliado, sendo ns $=$ não-significativo.

\section{CONCLUSÕES}

1-Os ramos porta-borbulhas da cultivar Montenegrina, provenientes de ambiente protegido, mantêm-se viáveis por 90 dias sem tratamento com fungicida e por 180 dias se submetidos a um tratamento com fungicida no momento de seu armazenamento.

2-Os ramos porta-borbulhas da cultivar Valência, coletados de ambiente protegido, mantêm-se viáveis por 180 dias, sem a necessidade de tratamento com fungicida.

3-O teor de substâncias de reserva dos ramos portaborbulhas da tangerineira 'Montenegrina' sofre redução significativa ao longo do período de conservação.

\section{REFERÊNCIAS}

BERGAMIN FILHO, A.; et al. (Ed.). Manual de fitopatologia. 3. ed. São Paulo: Agronômica Ceres, 1995. 2 v, 919 p.

BISSOLI, M. C. et al. Efeito do período de armazenamento sobre a viabilidade das borbulhas de quatro espécies cítricas. In: CONGRESSO BRASILEIRO DE FRUTICULTURA, 9., Campinas, 1987. Anais...Campinas: Sociedade Brasileira de Fruticultura, 1988. v.1, p.347-350.

CITROGRAF MUDAS. Técnicas de plantio. Disponível em: $<$ http://www.citrograf.com.br>. Acesso em: 27 nov. 2005.

ECKERT, J. W.; SOMMER, N. F. Control of diseases of fruit and vegetables by postharvest treatment. Annual Review of Phytopathology, St. Paul, v. 5, p.391-433, 1967.
FOCHESATO, M. L. Substratos e porta-enxertos na produção de mudas cítricas em ambiente protegido. $2005.91 \mathrm{f}$. Dissertação (Mestrado em Fitotecnia) - Faculdade de Agronomia, Universidade Federal do Rio Grande do Sul, Porto Alegre, 2005.

GALLI, M. J. A.; GUIRADO, N. Conservação de borbulhas de citros in vitro. Ecossistema, Campinas, v. 18, p.156-160, 1993.

HOAGLAND, D.R.; ARNON, D.I. The water-culture method for growning plants without soil. Berkley, Universidade da California, 1950.347p. (California Agricultural Experimental Station Circular)

LIMA, S. F. F. et al. Avaliação da viabilidade de hastes portaborbulhas de citros após armazenamento em baixa temperatura $\mathrm{e}$ tratamento com ANA, GA3 e 2,4-D. In: CONGRESSO BRASILEIRO DE FRUTICULTURA, 27., 2002. Belém. CD-ROM.

LUVISI, D. A.; SOMMER, N. F. Polysthylene liners and fungicides for peaches and nectarines. Proceedings of the American Society of Horticulture Sciense, Davis, v.76, p.146-155, 1960.

ROMEIRO, S. et al. Embalagem e tratamento químico na conservação de ramos porta-borbulhas de laranjeira 'Natal' em câmara fria. Laranja, Cordeirópolis, v.22, n.2, p.425-433, 2001.

SOUZA, P. V. D. de. Efeito de concentração de etefon e pressões de pulverização foliar no raleio de frutinhos em tangerineiras (Citros deliciosa Tenore) cv. 'Montenegrina'. 1990. 139 f. Dissertação (Mestrado em Fitotecnia) - Faculdade de Agronomia, Universidade Federal do Rio Grande do Sul, Porto Alegre, 1990.

TEIXEIRA, S. L. et al. Influência do período pós-colheita das hastes de cítrus sobre a qualidade das borbulhas para enxertia. Revista Ceres, Viçosa, v.18, n.99, p. 406-417, 1971. 